\title{
PReS-FINAL-2133: Drug survival and switching of biological agents in systemic juvenile idiopathic arthritis
}

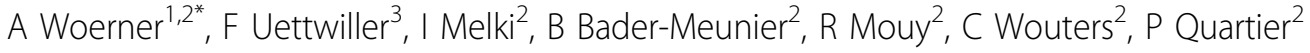 \\ From 20th Pediatric Rheumatology European Society (PReS) Congress \\ Ljubljana, Slovenia. 25-29 September 2013
}

\begin{abstract}
Introduction
Several biologic agents have become available for the treatment of systemic juvenile idiopathic arthritis (SJIA) over the last decade. Prescription strategies may depend on disease course, which is heterogeneous and other factors including the availability of biological agents, ongoing clinical trials and National marketing authorizations.
\end{abstract}

\section{Objectives}

To assess drug survival of biological agents in SJIA patients and to describe reasons for switching or discontinuating biologic treatment.

\section{Methods}

A retrospective observational study was conducted on SJIA patients treated in a French pediatric rheumatology reference center using the CEMARA register, a nationwide information system for rare diseases. We included patients who started biotherapy between 2005 and 2012 with a follow-up of at least 6 months after treatment initiation. Factors for switching or discontinuation of a biological agent were assessed.

\section{Results}

74 SJIA patients were included, with 41 female and 33 male subjects and a median age of 4.1 years at diagnosis [range 9 months to 15.1 years]. Median disease duration before starting the first biological agent was 17.3 months [range 1.7 to 107]. The cumulative follow up on biologics represented 266.5 patient-years. Concomitant treatment included non-steroidal anti-inflammatory drugs in $94 \%$, systemic steroids in $84 \%$ and disease-modifying anti-rheumatic

${ }^{1}$ Pediatric Rheumatology, University Children's Hospital, Basel, Switzerland Full list of author information is available at the end of the article drugs [7 methotrexate, 1 hydroxychloroquine, 1 leflunomide] in $12 \%$ at onset of biologic treatment. First-line biological agents were anakinra (ANA) in 45 patients, canakinumab (CAN) in 13, tocilizumab (TCZ) in 3, etanercept (ETA) in 12 and adalimumab (ADA) in 1 patient. At 3 months, drug survival for ANA versus CAN versus TCZ versus ETA as first-line biological therapy was $82 \%$ versus $100 \%$ versus $100 \%$ versus $67 \%$ percent, respectively. At $12 / 24$ months, drug survival for ANA was $55 / 55 \%$, for CAN $76 / 69 \%$, for TCZ $67 / 67 \%$ and for ETA $58 / 58 \%$, respectively. With first-line treatment, clinical remission was obtained in 55/69/67/9\% of ANA/CAN/TCZ/ETA treated patients, respectively.

35/15/33/63\% of ANA/CAN/TCZ/ETA treated patients switched to a second biological agent. At 3/12/24 months of second-line treatment, drug survival was $80 / 20 / 20 \%$ for ANA, $67 / 67 / 33 \%$ for CAN, 100/100/40\% for TCZ and $67 / 67 / 33 \%$ for ETA. One patient was switched from ETA to abatacept with a drug survival of 73.6 months. $26 \%$ and $4 \%$ of the patients experienced a switch to a third and fourth biological agent, respectively. In total, $64 \%$ of the patients achieved clinical remission with one or up to four biological agents.

Reasons for switching treatment were lack of efficacy in $37 \%$, adverse events in $21 \%$, loss of response to treatment in $32 \%$ and patient's/parent's choice in $10 \%$. Biological treatment was stopped in $10.8 \%$ of the patients due to inactive disease after a median time of 35.1 months [range 9 to 69 months]. Relapse of symptoms occurred in $42 \%$ after cessation of biotherapy.

\section{Conclusion}

Switching to a second or third biological agent is an appropriate approach for treatment of SJIA. Median drug 
survival was comparable for ANA, CAN and TCZ when used as a first line biologic.

\section{Disclosure of interest}

A. Woerner Grant/Research Support from: Novartis, Consultant for: Roche, F. Uettwiller: None declared., I. Melki: None declared., B. Bader-Meunier Grant/Research Support from: Abbvie, Chugai-Roche, Novartis, Pfizer, Consultant for: Abbott/Abbvie, BMS, Chugai-Roche, Novartis, Pfizer, Servier, SOBI, R. Mouy Grant/Research Support from: Abbvie, Chugai-Roche, Novartis, Pfizer, Consultant for: Abbott/Abbvie, BMS, Chugai-Roche, Novartis, Pfizer, Servier, SOBI, C. Wouters: None declared., P. Quartier Grant/Research Support from: Abbvie, ChugaiRoche, Novartis, Pfizer, Consultant for: Abbott/Abbvie, BMS, Chugai-Roche, Novartis, Pfizer, Servier, SOBI, Speakers Bureau: Chugai-Roche, Novartis, Pfizer.

\section{Authors' details}

${ }^{1}$ Pediatric Rheumatology, University Children's Hospital, Basel, Switzerland.

${ }^{2}$ Department of Pediatric Immunology, Hematology and Rheumatology,

Hôpital Necker-Enfants Malades, Paris, France. ${ }^{3}$ Allergology and Clinical

Immunology Unit, Clocheville Hospital, Tours, France.

Published: 5 December 2013

doi:10.1186/1546-0096-11-S2-P146

Cite this article as: Woerner et al:: PReS-FINAL-2133: Drug survival and switching of biological agents in systemic juvenile idiopathic arthritis. Pediatric Rheumatology 2013 11(Suppl 2):P146.
Submit your next manuscript to BioMed Central and take full advantage of:

- Convenient online submission

- Thorough peer review

- No space constraints or color figure charges

- Immediate publication on acceptance

- Inclusion in PubMed, CAS, Scopus and Google Scholar

- Research which is freely available for redistribution

Submit your manuscript at www.biomedcentral.com/submit 